\title{
Seth Carlo Chandler Jr.: The Discovery of Variation of Latitude
}

\author{
M.S. Carter \\ US Naval Observatory, Washington, D.C., USA \\ W.E. Carter \\ University of Florida, Gainesville, FL, USA
}

Abstract. It took Seth Carlo Chandler Jr. just one year to discover the 14 month and annual components of the variation of latitude (polar motion) that had eluded the most talented astronomers for more than a century. He succeeded where those before him had failed because: he used a global set of observations that had been painstakingly collected by astronomers of many nationalities over more than 150 years; he ignored the common wisdom that unexpected annual variations in astronomical observations were always caused by temperature effects on instruments or atmospheric refraction anomalies; and he was not misled by the theory, which predicted that the Eulerian wobble must have a period of approximately 10 months. Chandler was a true amateur only in the sense that he pursued astronomy out of love, while making his living as an actuary. He began his scientific training at the youthful age of 15 under the tutelage of Benjamin Pierce, perhaps the greatest American mathematician of that time. He then became: a private assistant to Benjamin Apthorp Gould, Jr., an aide to Gould while employed by the US Coast Survey, and Assistant Editor to Gould for the Astronomical Journal. It would be impossible to understand and appreciate Chandler's achievements without recognizing his relationship with Gould, his brilliant mentor and lifelong colleague - the man he once described as his "Magnus Apollo."

In 1901 Chandler announced that the 14 month motion was not a simple oscillation but was in itself a compound motion consisting of the previously discovered 428 day component, and a much smaller 436 day component, whose reality was "beyond reasonable doubt." The beating of two such components would result in a rapid change in the phase and amplitude of the Chandler motion at intervals of about 80 years. If Chandler was correct, in about 2010 , give or take perhaps five years, we should see the next occurrence of this phenomenon. With the International Earth Rotation Service in operation there should be no difficulty in detecting and quantifying such an event, very nearly one century after Chandler's death. 


\section{Early searches for variation of latitude fail}

Theoretical studies performed by the Swiss scientist Leonhard Euler, concerning the dynamics of rotating bodies, first revealed that the axis of figure and axis of rotation of Earth may not be coincident, and as a consequence, Earth may wobble slightly about the axis of rotation. The period of the wobble, which could be computed from the flattening of Earth alone assuming a rigid body, was estimated to be approximately 10 months (306 days).

In 1880 the British astronomer A. M. W. Downing reviewed the status of the search for variation of latitude (Downing, 1880), finding the following results. In 1842 the Prussian astronomer Friedrich Wilhelm Bessel had reported an unsuccessful attempt to detect a ten-month oscillation in his observations, collected in Königsberg. The British scientist James Clerk-Maxwell had examined observations of Polaris, collected at the Royal Greenwich Observatory during the years 1851 to 1854 . He found signs of some variation of latitude during certain periods, but concluded that "this result is to be regarded as very doubtful" and that "more observations would be required to establish the existence of so small a variation at all." C. A. F. Peters and Magnus Nyrén had analyzed observations from the Pulkovo Observatory, in St. Petersburg, Russia, finding some suggestions of the phenomenon, but concluding that there "was not constancy of magnitude or phase in the variation of apparent latitude."

Downing, himself, analyzed observations of Polaris collected at the Royal Greenwich Observatory during a ten-year period, from 1868 to 1877. Simply from an inspection of monthly means, he noted an apparent annual variation, but no ten-month variation. Nonetheless, he used least-squares methods to estimate the amplitude and phase of a ten-month variation, finding a variation with an amplitude of approximately seven hundredths of a second of arc. He concluded his paper with the statement "if a short series of observations are used we cannot be sure that we have satisfactorily got rid of accidental errors, or errors (possibly) depending on the refraction .... if we discuss a sufficiently long series of observations to eliminate these errors, we make what may be an illegitimate assumption - viz., that the variation remains constant."

Following Downing's report Simon Newcomb reviewed observations collected at the US Naval Observatory. Newcomb concluded that any variation of latitude must be smaller than about five hundredths of a second of arc, if it existed at all. By 1884 the once strong interest in searching for the elusive phenomenon had severely waned.

\section{Harvard Observatory, 1884-1885: Tests of a new instrument yields intriguing results}

As a young man, while employed at the US Coast Survey, Seth Carlo Chandler, Jr. (Figure 1) had learned to operate a visual zenith telescope (VZT) to determine astronomic latitude and longitude. He was displeased that an observer spent as much as forty to fifty percent of his time at the instrument just determining the amount by which the VZT was out of level, because of the difficulty of working with sensitive and easily disturbed spirit levels. When Chandler married, he left the Coast Survey and took employment as an actu- 
ary at a life insurance company, but he could not give up astronomy for long and soon became an active "amateur" astronomer. He set out to build a more observer-friendly and less costly instrument to replace the VZT, by eliminating the spirit levels. He not only designed a new self-leveling instrument (Figure 2), he also developed a new observing program to take the greatest advantage of the new instrument. Instead of observing stars as they transited the observer's meridian, he observed stars at equal altitudes, i.e., along the same almucantar, on either side of the meridian. The observer simply had to record the times that stars crossed an array of lines on the reticle. No readings of spirit levels, graduated circles, or eyepiece micrometer were required. Chandler called his new instrument an Almucantar, and it was far simpler and less expensive than the VZT. But, was it as accurate?

During April 1884 until May 1885 Chandler used his Almucantar to make a series of determinations of the latitude of the Harvard Observatory. His purpose was to test the accuracy of the Almucantar, not to look for variation of latitude, however his observations clearly showed a systematic change in the latitude. Chandler published his results in the German journal Astronomische Nachrichten (Chandler, 1885) pointing out the systematic change in the latitude values determined during the time series, but not claiming that they were real. During the next few years Chandler devoted most of his research to the study of variable stars and computing orbital parameters for comets. His two hundred plus page final report entitled "The Almucantar" was published in the Annals of The Astronomical Observatory of Harvard College (Chandler, 1887). Still, Chandler did not assert that the apparent variation in latitude was real, although he made it very clear that he could identify no source of error that would explain the observed variation.

\section{Berlin Observatory, 1884-1885: New measurement of aberration yields unexpected results}

In one of those strange coincidences in the history of science, the German scientist Friedrich Küstner, an observer at the Berlin Observatory, also made a series of observations during 1884 and 1885, that captured the variation of latitude. Küstner's purpose was even further from looking for variation of latitude than Chandler's - he was not attempting to determine latitude at all, but rather to better determine the constant of aberration. Recent measurements of the speed of light by the American scientist Albert Abraham Michelson (1852-1931), had opened the possibility of improving the knowledge of the size of our solar system if knowledge of the aberration could be improved. Ironically, Küstner decided to use the Talcott method of observation, developed in 1834 by the American, Captain John Talcott, of the U.S. Army Corps of Engineers, to accurately determine latitude.

The immediate results of Küstner's work were disappointing - the constant of aberration he derived from the observations was impossibly small. He could find no source of error in the instrument large enough to explain the disappointing results. He was concerned that the observations might be contaminated with systematic errors caused by a seasonal non-symmetry of the atmospheric refraction. Since the Talcott method consisted of observing stars at very nearly 


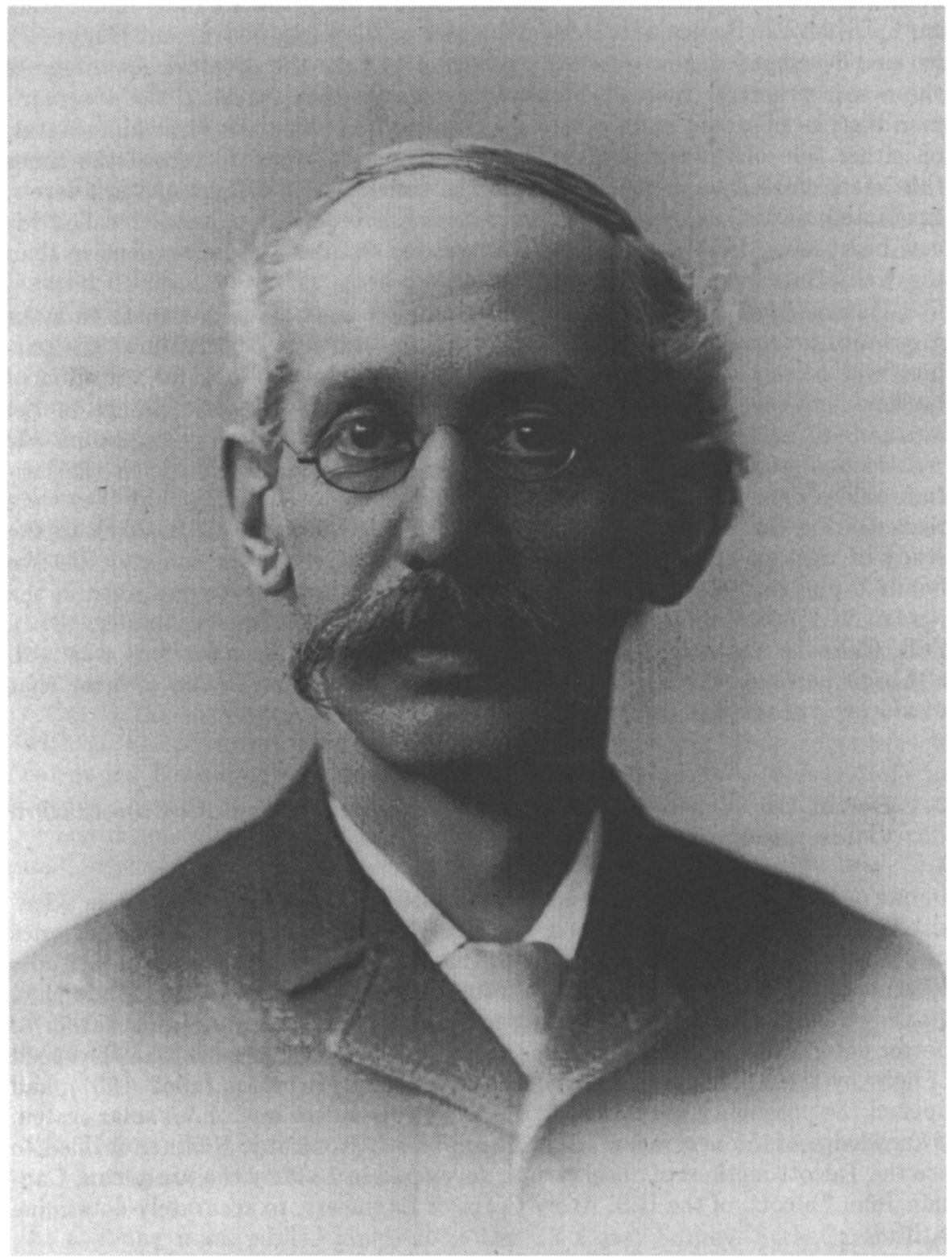

Figure 1. This Photograph of Seth Carlo Chandler Jr. was taken circa 1900 . 


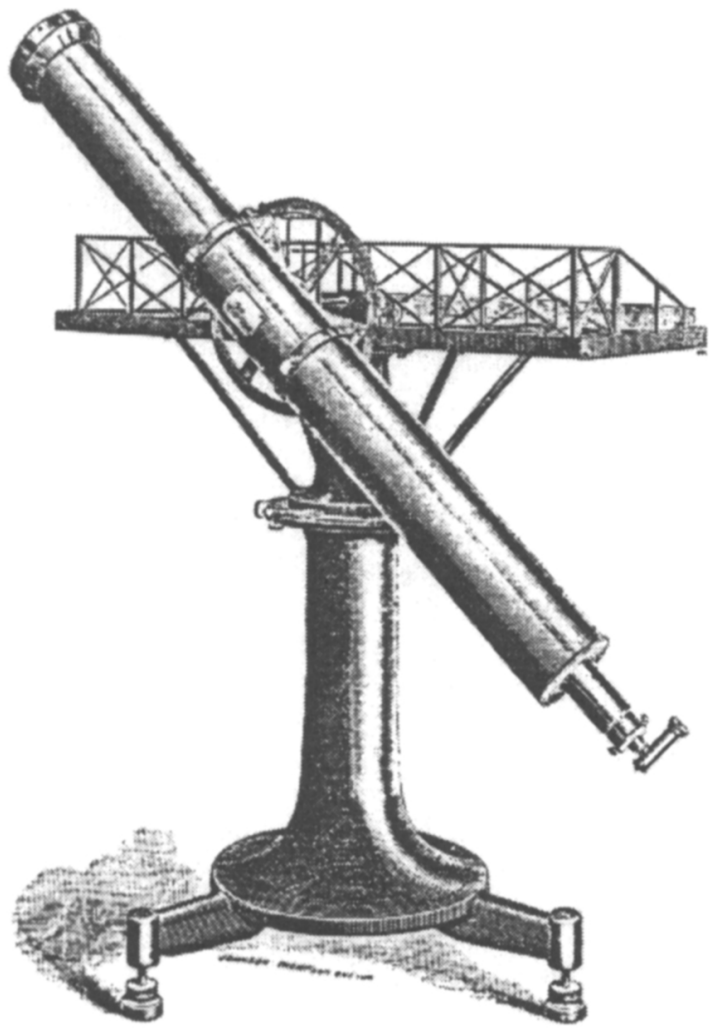

THE ALMUCANTAR:

Figure 2. Sketch of the Almucantar, reproduced from Chandler (1887). 
equal altitudes north and south of the observer, the atmosphere would have to have had some peculiar structure, such as a north-south slope of the layers of equal density.

Küstner put aside his analysis of the troubling observations and went on to other work. By the time that he returned to his study of the data nearly two years later, Chandler's paper had been published in Astronomische Nachrichten, and Küstner may well have been more prepared to accept the possibility that the latitude of the Berlin Observatory really had changed during the period of his observations. He found that observations on identical pairs of stars recorded in 1884 and 1885 , under nearly identical conditions, produced latitudes differing by more than two tenths of a second of arc. The uncertainty of the change in latitude, computed from seven identical pairs, was less than three hundreds of a second of arc. Küstner felt justified in ruling out anomalous atmospheric refraction and errors in the proper motions of the stars, concluding that the latitude of the observatory had changed, and in 1888 published his work. He did not address the periodic nature of the variation in his paper, which meant that questions about any discrepancy between the observed motion and theoretical period of ten months were never raised.

\section{Combination of Harvard and Berlin Observations reveal Chandler motion}

When Chandler learned of Küstner's results he knew that the change he had detected in the latitude of the Harvard Observatory was real and he set out immediately to learn the law that governed the phenomenon. Chandler had extended his observations with the Almucantar after the publication of his paper reporting his initial results, and in November 1891, he published two papers (Chandler, 1891a and 1891b) in which he presented detailed comparisons between his Almucantar results and Küstner's observations. He concluded that the two series were fully consistent, noting that:

"in the autumn of 1884 , when the Cambridge latitudes were smallest, those of Berlin were largest; while in the spring of 1885 this condition was reversed. The break of four months in the Berlin series unfortunately prevents our fixing the epoch of minimum with certainty, but probably it occurred in January and February of 1885; while at Cambridge this phase was in September or October or 1884. If the values in the table be charted and curves drawn, it will be evident on trial that they can be made to correspond satisfactorily by assuming that the occurrence of any given phase at Cambridge preceded that at Berlin by about one-quarter of the period of 427 days, but not at all by assuming that it followed by that amount. This would apparently indicate that the polar motion is from west to east, or in the direction of increasing right ascension."

Chandler then proceeded to show that observations from the Pulkovo and Washington observatories during the same period displayed the same variation. Together, the complete set of observations showed "a revolution of the earth's pole in a period of 427 days, from west to east, with a radius of thirty feet, measured 
at the earth's surface." Today this component of polar motion is referred to as the Chandler motion.

\section{Discovery of the annual component and other aspects of polar motion}

One year after discovering the 14-month motion of the pole, in November of 1892 , Chandler announced the discovery of the annual component of the variation of latitude, with estimates of the periods, amplitudes, phases and directions of rotation of both components (Chandler, 1892b). He continued to expand his analysis, eventually including more than thirty-three thousand observations collected by seventeen observatories (four of them in the southern hemisphere), with twenty different instruments, and nine distinct methods of observation. His many findings were far too extensive to present here. They included investigation of secular drift of the pole, concluding that its reality was doubtful, and placing a maximum magnitude on it of about three milliseconds of arc per year (Chandler 1892a). His estimates of the magnitude and direction closely match those found today, and there is still disagreement as to the reality of the phenomenon, even though it is in good agreement with current measurements of the glacial rebound. Chandler also devoted a great deal of time to refining his estimates of the annual term, concluding that the motion was not circular, but elliptical, and that the orientation of the ellipse changed systematically with time. Chandler attributed the changes in the annual term to "changing meteorological conditions," but apparently never completed his research to show this connection quantitatively.

Chandler eventually became convinced that the 14-month term was actually compound, composed of a 428-day primary component and a much smaller (onefourth to one-third the amplitude) 435-day component. This issue is discussed in more detail below.

\section{Seth Chandler Jr.: Unknown "amateur" American astronomer}

Seth Carlo Chandler, Jr., was an eighth generation American born in Boston Massachusetts, on September 16, 1846 (Hurd, 1902). He was the fourth of six children born to Seth Carlo Chandler Sr., and Mary Jane Cheever. There is no indication that Seth Jr. was a child prodigy, but apparently he was fascinated by the intricate mechanical workings of the household clocks and sewing machine, adjusting and repairing them as needed. Seth Jr. graduated from the Boston English High School in 1861, at age fifteen. Had he planned to go to college he would have attended the Boston Latin High School, but his plans were undoubtedly strongly influenced by his father. Seth Sr. was a successful merchant, being a member of Roby and Company, dealers in hay, coal and other commodities. His grandfather Cyril had been a tanner, his great grandfather Captain Seth Chandler had been a farmer and tax collector, and his great great grandfather Joseph Chandler had been a saddler by trade, but also owned and resided on a large farm. Generation after generation of Chandlers had done well without college degrees and it is not surprising that a successful Yankee Trader such as Seth Sr. would be more impressed with the bottom line of a ledger sheet than a college diploma. 
It appears that Seth Jr. would have had little choice but to follow in his father's footsteps had he not been drawn into science by a peculiar turn of events. During his final year in high school Seth Jr. was given an opportunity to work for Benjamin Pierce, perhaps the greatest American mathematician of his time. Pierce was associated with the Harvard College Observatory, and put his young assistant to work doing mathematical computations to reduce astronomic observations. Seth Jr. must have performed his duties exceptionally well because after graduating from high school, with the recommendation of Benjamin Pierce, he became a private assistant to Benjamin Apthorp Gould, Jr. (Carter and Carter, 1995).

Gould had studied under Benjamin Pierce and graduated from Harvard in 1844 , at the age of nineteen, with distinctions in mathematics and physics (James, 1940). No American university offered a doctorate degree in astronomy in the 1840 s and Gould decided that he must travel to Europe to complete his formal education. After first spending some time at the Royal Greenwich Observatory and the Paris Observatory, Gould decided to go to Germany, where Johann Franz Encke accepted him as a student at the Berlin Observatory. After working for a year in Berlin, Gould was accepted as a student by Carl Friedrich Gauss, the most renowned mathematician of the nineteenth century, and in 1847 Gould moved to the University of Göttingen. Gould concluded that the German instrumentation, scientific methods, and focus on applied astronomy were all superior to the English instrumentation, scientific methods, and focus on physical astronomy. He made a personal vow to himself to introduce and champion the German system of astronomy in the United States, with the goal of elevating the quality of scientific research in the United States to European standards.

It took Gould only one year to complete his Doctorate studies under Gauss. After graduating from the University of Göttingen, Gould spent several additional months traveling through Europe, visiting observatories and meeting the leading astronomers of his time. His most important stop was probably to visit Heinrich Christian Schumacher, who, in 1821, had founded and was then still the editor of the scientific journal Astronomische Nachrichten. Gould was certain that he had found the key that would launch his plans to upgrade American science - to start an American journal with the same high standards as $A s$ tronomische Nachrichten. In 1849 Gould launched his new scientific journal, which he named simply Astronomical Journal, and which quickly gained recognition as a first quality scientific journal, both in America and in Europe.

It is hard to imagine that Chandler would not find Gould worthy of emulation and Gould quickly became much more than a mentor to Seth Jr. - he was more of a second father. Chandler's views on the practice of science, which would guide him throughout the rest of his lifetime, were developed during these formative years, directly under the day-to-day supervision and guidance of Gould. His close association with Gould, a bigger than life character about whom the winds of conflict seemed always to blow, provided Chandler such unique opportunities and recognition as being editor of the Astronomical Journal, but also a ready supply of critics. 


\section{Giving credit where credit is due}

In science, assigning credit to an individual for the discovery of a phenomenon is sometimes free of controversy. For example, few would argue that the discovery of special and general relativity should be accorded to any person other than Albert Einstein. More commonly, however, the person to whom credit for the discovery of a new phenomenon should be accorded is less clear, and conflicting claims can result. It is clear that Euler performed the theoretical work that first suggested the possible existence of the variation of latitude, or polar motion. However, his model, as applied to Earth, was overly simplistic, producing an error in the predicted period of the motion of about forty percent. The issue was further complicated by the failure of the scientific community to realize that the periodic relocation of mass on Earth could cause yet another component of polar motion, the forced annual motion.

For more than a century after Euler's theoretical work, some of the best known astronomers in the world failed to detect polar motion, even while struggling to identify the source of unexpectedly large variations in their observations. In hindsight it seems clear that these scientists failed because:

1. They limited their investigations to a single observatory, instrument, or series of observations.

2. They focused too closely on looking only for a variation of ten months, as predicted by theory.

3. They automatically assigned annual variations in the observations to atmospheric refraction and/or temperature affects on their instruments.

4. The beating of the annual and 14-month terms meant that the motion of pole alternately appeared and disappeared, making it difficult to detect.

Seth Carlo Chandler, Jr., was the first scientist to identify and renounce these mistakes. He collected observations from as many sources as possible, made by different observers using different types of instruments at widely separated observatories, and he analyzed these observations without regard to the predictions of theory. Adding to his credit, Chandler published each step of his progress, with delays counted in days rather than years - an openness unheard of in that era. He made some mistakes along the way, but it still took him just one year, from November 6,1891 , until November 4,1892 , to discover and publish his findings that the period of the Eulerian motion was not ten months, but fourteen months, and that there was a second component with a period of twelve months.

Chandler's results were not speculative, but based on the in-depth analysis of existing observational data amassed over nearly two centuries. He determined the periods, amplitudes, phases and directions of rotation of each component. His analysis eventually included more than thirty-three thousand observations collected by seventeen observatories (four of them in the southern hemisphere), with twenty different instruments, and nine distinct methods of observation. These numbers are impressive even today with our digital computers, but Chandler did all his computations, using the method of least-squares, by hand. His results were fully documented and beyond rational dispute. 
Variation of latitude, or polar motion, was discovered by Seth Carlo Chandler Jr. Others may have come close to (or in the case of Küstner succeeded in) detecting a change in the latitude of a specific observatory, but Chandler was the first to reveal the true nature of the phenomenon, and that nature was very different than had been expected from theory. The history of the international campaign organized by the IGA should not be tarnished by false claims that it verified the existence of polar motion, rather it should rightly be credited with leading to the establishment of the International Latitude Service, a model of international cooperation that continued for more than eighty years.

\section{One of Chandler's findings remains to be tested}

For several years after Chandler had discovered the fundamental aspects of the variation of latitude he continued to reduce and analyze historical observations, eventually piecing together a complete record from 1820 until the early 1900s. As he refined his analysis he became convinced that the fourteen-month component was not a simple single frequency oscillation, but was itself a complex motion involving two or more components. In 1901 he announced the discovery of a 436-day component that was considerably smaller than the 428-day motion, whose reality was "beyond reasonable doubt" (Chandler 1901). The beating of two components of such nearly equal frequencies but disparate amplitudes would generate a very distinctive pattern in the motion of the pole. Chandler described the pattern and then boldly predicted "We shall soon have a ... test of the law in its operation which ... ought to shorten to the minimum value, 415 days, within the next few years. Of course, an accurate prediction cannot be made as to when this interesting phase will become perceptible, because the length of the harmonic cycle, which depends on the difference of the two component periods, is imperfectly defined by existing observations." Even with this caveat, Chandler had taken a risky step by predicting such a pronounced variation in the motion of the pole. His prediction did not come true in 1910 , nor by his death in 1913, and it was soon forgotten by the scientific community. But some fifteen years later, circa 1926, an event just as Chandler had predicted did occur.

If Chandler was correct in his contention that the 14 month variation is actually composed of two closely matched components, there should be a dramatic change in the apparent amplitude and phase of the Chandler motion in about 2010, give or take perhaps five years. The new IERS will capture any such change in such exquisite detail that there should be no difficulty settling the century old conflict. If Chandler's model is proven correct, he will once again have bested the international scientific community, very nearly one century after his death.

\section{References}

Carter, W. E. and M. S. Carter, 1995, Seth Carlo Chandler, Jr., 1846 to 1913, A Biographical Memoir, National Academy of Sciences, National Academy Press, Washington D.C. 
Chandler, S. C., 1885, On the Latitude of Harvard College Observatory, Astronomische Nachrichten, No. 2672, Bands $112-120$.

Chandler, S. C., 1887, The Almucantar, Annals of the Astronomical Observatory of Harvard College, John Wilson and Son, University Press.

Chandler, S. C., 1891a, On The Variation of Latitude, I, Astronomical Journal, 248, 59-61.

Chandler, S. C., 1891b, On The Variation of Latitude, II, Astronomical Journal, 249, 65-70.

Chandler, S. C., 1892a, On The Supposed Secular Variation of Latitudes, Astronomical Journal, 255, 113-116.

Chandler, S. C., 1892b, On The Variation of Latitude, VII, Astronomical Journal, 277, 97-101.

Chandler, S. C., 1901, On A New Component of the Polar Motion, Astronomical Journal, 490, 79-80.

Downing, A. M. W., 1880, On the Variation of Latitude, Monthly Notes R. A. $S$.

James, M. A., 1940, Elites in Conflict, the antebellum clash over Dudley Observatory, Rutgers University Press.

Hurd, C. E., 1902, New England Library of Genealogy and Personal History, Representative Citizens of the Commonwealth of Massachusetts, compiled under the editorial supervision of Charles Edwin Hurd, New England Publishing Company, Boston, Massachusetts. 